\title{
Effect of Nb Content on Deformation Textures and Mechanical Properties of Ti-18Zr-Nb Biomedical Alloys*1
}

\author{
Hirobumi Tobe ${ }^{1, * 2}$, Hee Young $\mathrm{Kim}^{1, * 3}$ and Shuichi Miyazaki ${ }^{1,2, * 3}$ \\ ${ }^{1}$ Institute of Materials Science, University of Tsukuba, Tsukuba 305-8573, Japan \\ ${ }^{2}$ School of Materials Science and Engineering, Gyeongsang National University, \\ 900 Gazwadong, Jinju, Gyeongnam 660-701, Korea
}

Recently, $\beta$-type Ti alloys composed of non-toxic elements such as $\mathrm{Nb}, \mathrm{Ta}, \mathrm{Zr}$, Mo and $\mathrm{Sn}$ have been studied for biomedical applications. The present author's research group has also developed these alloys including Ti-Zr-Nb as new biomedical superelastic materials. They reveal strong textures which are formed during thermo-mechanical processing and cause the anisotropy in mechanical properties. In this study, the effect of $\mathrm{Nb}$ content on the deformation texture of Ti-18Zr-Nb alloys was investigated. The anisotropy in mechanical properties of Ti-18Zr-Nb alloys was also investigated. Ti-18Zr-(15 18) $\mathrm{Nb}$ (at\%) alloy ingots were fabricated by an Ar arc melting method and then homogenized at $1273 \mathrm{~K}$ for $7.2 \mathrm{ks}$. The ingots were cold rolled with a reduction up to $99 \%$ in thickness. For the as-rolled alloys, a weak $\gamma$-fiber texture was observed in Ti-18Zr- $(15,16) \mathrm{Nb}$ alloys, whereas a well developed $\{001\}\langle 110\rangle$ texture was confirmed in the Ti-18Zr-18Nb alloy. The former alloys revealed weak anisotropy in Young's modulus due to the weak texture, while the latter alloy exhibited strong anisotropy due to the strong texture. [doi:10.2320/matertrans.MA200908]

(Received July 15, 2009; Accepted September 4, 2009; Published November 25, 2009)

Keywords: shape memory alloys, biomaterials, titanium alloys, texture, mechanical properties

\section{Introduction}

CP-Ti and Ti-6Al-4V (mass\%) have been widely used for biomaterials such as bone plates and artificial hip joints. However, the stress shielding effect has been pointed out because the Young's moduli of these alloys are over $100 \mathrm{GPa}$, which is much higher than that of human bone ( $20 \mathrm{GPa})$. Therefore, $\beta$-type Ti alloys exhibiting a low Young's modulus which is more closer to that of human bone have attracted attention recently. ${ }^{1,2)}$ On the other hand, Ti-Ni shape memory alloys have been successfully applied as biomedical devices such as guide wires, stents and orthodontic wires. However, the worry about the risk of Ni-hypersensitivity has led to developing new biomedical shape memory alloys consisting of non-toxic elements, and many $\beta$-type Ti-base shape memory and superelastic alloys have been developed by many researchers to date..$^{3-11)}$

The present authors have systematically investigated the effect of alloying elements, such as $\mathrm{Ta},{ }^{8)} \mathrm{Zr},{ }^{9)} \mathrm{Pt}^{10)}$ and $\mathrm{O}^{11)}$ which are less-toxic elements, on shape memory and superelastic properties of Ti-Nb alloys. Among the alloying elements, it has been shown that $\mathrm{Zr}$ is effective in increasing the transformation strain and suggested that the $\mathrm{Ti}-\mathrm{Zr}-\mathrm{Nb}$ system is promising for new biomedical shape memory and superelastic alloys. ${ }^{3,9)}$ Meanwhile, it has been reported that strong textures are formed in $\beta$-type Ti alloys by cold rolling and/or following heat treatment, causing the anisotropy in superelastic properties and mechanical properties. ${ }^{12-15)}$ However, there are few reports on the textures of the $\mathrm{Ti}-\mathrm{Zr}-\mathrm{Nb}$ alloys.

\footnotetext{
*1 This Paper was Originally Published in Japanese in J. Japan Inst. Metals 72 (2008) 965-969.

${ }^{* 2}$ Graduate Student, University of Tsukuba

${ }^{*}$ Corresponding authors, E-mail: heeykim@ims.tsukuba.ac.jp, miyazaki@ims.tsukuba.ac.jp
}

In this study, the effect of $\mathrm{Nb}$ content on the deformation texture was investigated for $\mathrm{Ti}-18 \mathrm{Zr}-\mathrm{Nb}$ alloys. The effect of the deformation textures on the mechanical properties was also discussed.

\section{Experimental Procedures}

Ti-18Zr-(15 18)Nb (at\%) ingots were fabricated by the Ar arc melting method. The ingots were sealed in a vacuum quartz tube and homogenized at $1273 \mathrm{~K}$ for $7.2 \mathrm{ks}$, followed by air-cooling. After the homogenization, phase constitutions were investigated by X-ray diffraction (XRD). There exist only the peaks corresponding to the $\beta$ phase in each alloy. The ingots were cold rolled to sheets at room temperature with a reduction up to $99 \%$ in thickness. The final thickness of the sheets was about $100 \mu \mathrm{m}$. Specimens for tensile tests and XRD measurements were cut by an electro-discharge machine from the sheets. The oxidized surfaces formed by the cutting were removed by chemical etching in a solution of $10 \mathrm{vol} \% \mathrm{HF}, 40 \mathrm{vol} \% \mathrm{HNO}_{3}$ and $50 \mathrm{vol} \% \mathrm{H}_{2} \mathrm{O}$ at room temperature. To investigate the anisotropy of mechanical properties within the rolling plane, tensile specimens were cut so that the tensile axes locate along three specific directions, i.e. rolling direction, direction tilting $45^{\circ}$ from the rolling direction and direction tilting $90^{\circ}$ from the rolling direction. Hereafter, these directions are termed RD, 45D and TD (transverse direction), respectively. Specimens for transmission electron microscope (TEM) observation were prepared by a twin-jet polishing technique.

Tensile tests were conducted along the RD, 45D and TD at room temperature in order to investigate mechanical properties and the anisotropy in the cold rolled specimens. Both ends of the tensile specimens were fixed with two chucks so that a gauge length becomes $20 \mathrm{~mm}$ and the strain of the specimens was determined by measuring the distance 

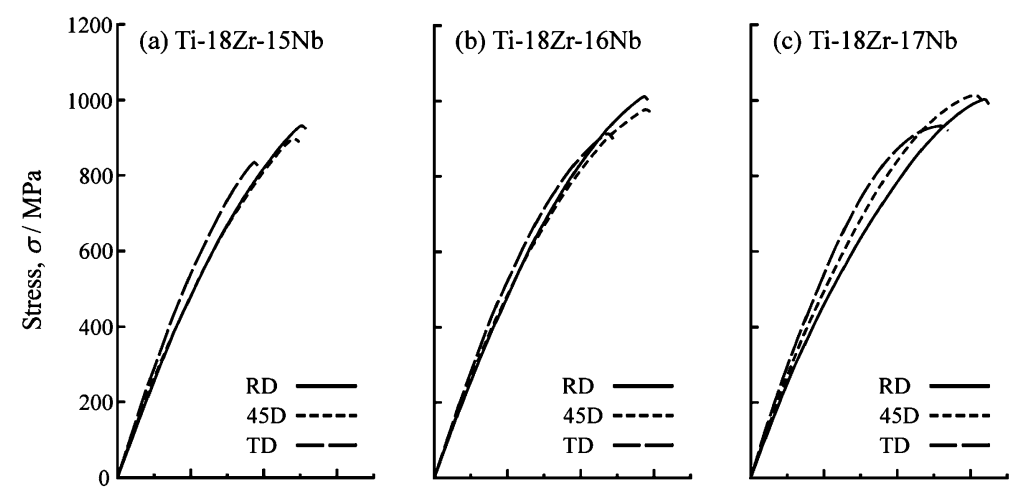

Strain, $\varepsilon(\%)$

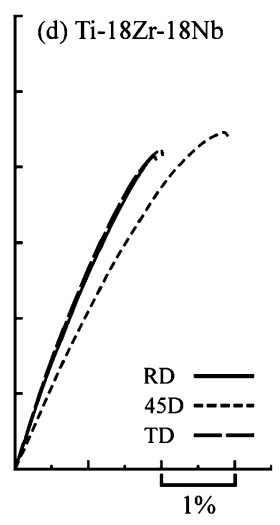

Fig. 1 Stress-strain curves obtained at room temperature for the cold rolled $\mathrm{Ti}-18 \mathrm{Zr}-(15 \sim 18) \mathrm{Nb}$ (at $\%$ ) alloys.

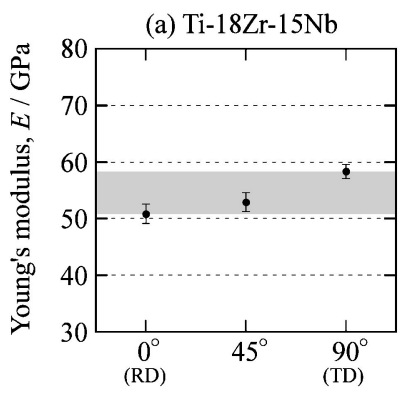

(b) Ti-18Zr-16Nb

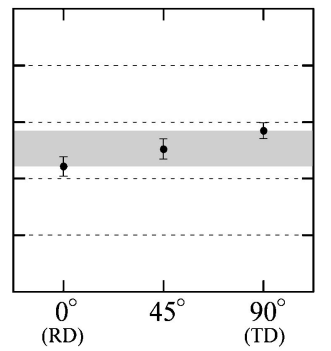

(c) $\mathrm{Ti}-18 \mathrm{Zr}-17 \mathrm{Nb}$

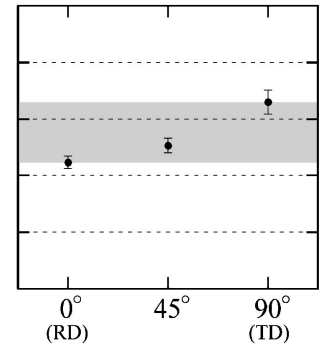

(d) Ti-18Zr-18Nb

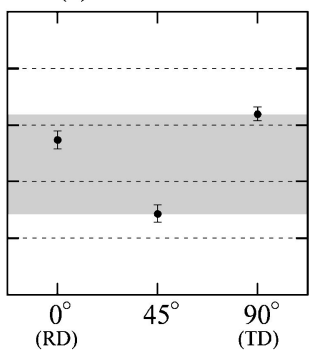

Angle from RD

between the chucks using a strain gauge extensometer. The strain rate of the tensile tests was $2.5 \times 10^{-4} \mathrm{~s}^{-1}$. Young's moduli of the specimens were determined by measuring the slope of the tangent around zero strain on a stress-strain curve. To investigate deformation textures formed in cold rolled specimens, XRD measurements were carried out at room temperature with a $\mathrm{Cu} \mathrm{K} \alpha$ radiation. Only the peaks corresponding to the $\beta$ phase were observed in all the cold rolled alloys, then pole figures were measured by the Schulz diffraction method for three crystal planes $\{110\},\{200\}$ and $\{211\}$ of the $\beta$ phase. Orientation distribution functions (ODFs) and inverse pole figures were calculated using the three pole figures. Microstructures of the cold rolled alloys were investigated by a TEM (JEOL2010F) operated at $200 \mathrm{kV}$.

\section{Results and Discussion}

\subsection{Mechanical properties and anisotropy}

Figure 1 shows stress-strain curves obtained at room temperature for the cold rolled $\mathrm{Ti}-18 \mathrm{Zr}-(15 \sim 18) \mathrm{Nb}$ (at \%) alloys. The tensile tests were conducted along the RD, 45D and TD for each alloy. The present authors have reported that a solution treated $\mathrm{Ti}-18 \mathrm{Zr}-15 \mathrm{Nb}$ (at \%) alloy shows superelasticity at room temperature. ${ }^{16)}$ Since the as-rolled specimens used in the present study are single $\beta$ phase, application of stress may induce superelasticity due to the martensitic transformation. However, as shown in Fig. 1(a), a clear yield point attributed to a stress-induced martensitic transforma- tion was not observed in the cold rolled specimen. It is considered that the high density of defects induced by the cold rolling suppressed the martensitic transformation. Each alloy shown in Fig. 1 exhibits a high tensile strength over $800 \mathrm{MPa}$ along each direction. Especially for the Ti-18Zr$(16,17) \mathrm{Nb}($ at $\%)$ alloys, extremely high strength over $1 \mathrm{GPa}$ was observed along the RD. Referring to the Young's modulus for each alloy along the RD, 45D and TD, distinct anisotropy was observed in the Ti-18Zr-18Nb (at\%) alloy, though the Ti-18Zr- $(15,16) \mathrm{Nb}$ (at\%) alloys exhibited weak anisotropy.

The in-plane anisotropy of the Young's modulus was compared in Fig. 2 for each cold rolled alloy. The gray region indicates the range of the values of Young's modulus in each alloy. The Ti-18Zr- $(15,16) \mathrm{Nb}$ (at\%) alloys exhibited a low Young's modulus of about $51 \mathrm{GPa}$ along the RD and slightly increased by tilting the orientation from the RD to the TD. The difference between the maximum and minimum values of the Young's moduli is only about $7 \mathrm{GPa}$ in the Ti-18Zr- $(15,16) \mathrm{Nb}$ (at\%) alloys. On the other hand, the Ti-18Zr-18Nb (at\%) alloy exhibited distinct anisotropy. The Young's moduli of $57 \mathrm{GPa}$ and $62 \mathrm{GPa}$ were observed along the RD and the TD, respectively. However along the 45D, extremely low Young's modulus of $44 \mathrm{GPa}$ was observed.

\subsection{Deformation textures and internal structures}

To investigate deformation textures and their effect on the anisotropy of Young's modulus, pole figures were measured by XRD for the Ti-18Zr-16Nb (at \%) and Ti-18Zr-18Nb 
(a) $\mathrm{Ti}-18 \mathrm{Zr}-16 \mathrm{Nb}$
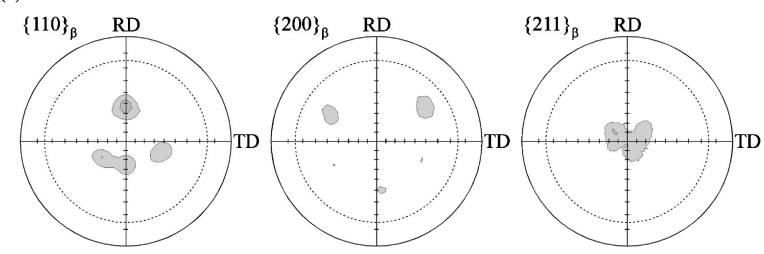

(b) Ti-18Zr-18Nb

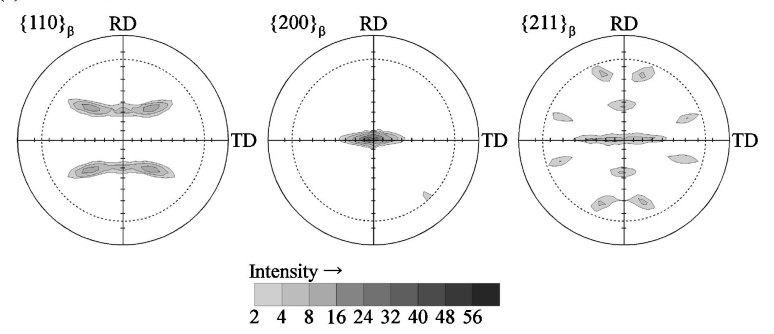

Fig. $3\{110\},\{200\}$ and $\{211\}$ pole figures of the cold rolled (a) Ti-18Zr$16 \mathrm{Nb}$ (at\%) and (b) Ti-18Zr-18Nb (at\%) alloys.

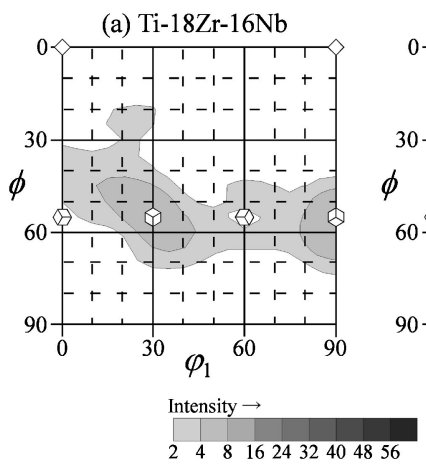

(b) $\mathrm{Ti}-18 \mathrm{Zr}-18 \mathrm{Nb}$

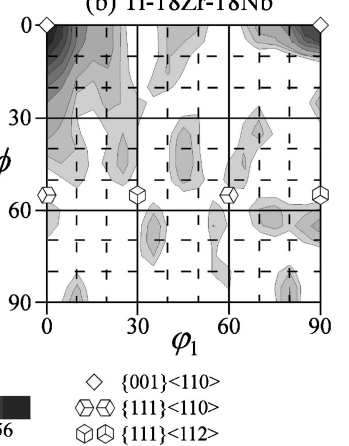

Fig. 4 Sections $\left(\varphi_{2}=45^{\circ}\right)$ of the orientation distribution functions for the cold rolled (a) Ti-18Zr-16Nb (at\%) and (b) Ti-18Zr-18Nb (at\%) alloys.

(at\%) alloys, where the former and the latter exhibited the weakest and the strongest anisotropy, respectively. Figure 3 shows $\{110\},\{200\}$ and $\{211\}$ pole figures obtained from the cold rolled Ti-18Zr- $(16,18) \mathrm{Nb}$ (at\%) alloys. The center of the pole figures corresponds to the normal direction (ND) of the rolling plane. The vertical direction and the horizontal direction of the pole figures correspond to the RD and the TD, respectively. The maximum pole density obtained from the Ti-18Zr-16Nb (at\%) alloy is lower than that of the Ti-18Zr$18 \mathrm{Nb}$ (at\%) alloy. On the other hand, a strong peak is observed at the center of the $\{200\}$ pole figure in the Ti$18 \mathrm{Zr}-18 \mathrm{Nb}($ at $\%)$ alloy, indicating that $\{200\}$ planes align preferentially to the rolling plane. In the $\{110\}$ pole figure, four strong peaks are symmetrically located at $45^{\circ}$ from the ND and $60^{\circ}$ both from the RD and TD. These results indicate that a well developed $\{001\}\langle 110\rangle$ texture is formed in the cold rolled Ti-18Zr-18Nb (at\%) alloy. ODFs were calculated using the three pole figures of both alloys. Figure 4 shows the $\varphi_{2}=45^{\circ}$ sections of the ODFs. The Ti-18Zr-16Nb (at\%) alloy exhibits a weak $\gamma$-fiber texture having a maximum density close to $\{111\}\langle 112\rangle$. Meanwhile, the Ti-18Zr-18Nb (at\%) alloy exhibits a strong $\{001\}\langle 110\rangle$ texture. The $\{001\}\langle 110\rangle$ deformation texture was also observed in Ti$22 \mathrm{Nb}-6 \mathrm{Ta}^{12)}$ (at $\left.\%\right)$ and $\mathrm{Ti}-24 \mathrm{Nb}-3 \mathrm{Al}^{13}$ ) (at\%) alloys cold rolled up to $99 \%$ in thickness. (a) Ti-18Zr-16Nb
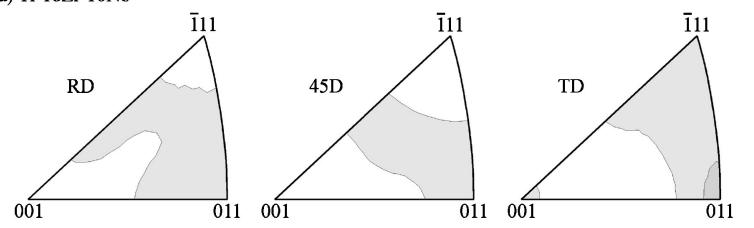

(b) Ti-18Zr-18Nb
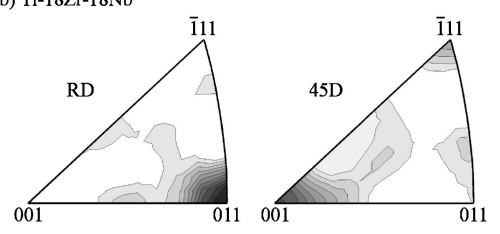

Intensity $\rightarrow$

\begin{tabular}{|lllllllllllllll}
\hline & & & & & & & & & & & & & \\
\hline 1 & 2 & 3 & 4 & 5 & 6 & 7 & 8 & 9 & 10 & 11
\end{tabular}

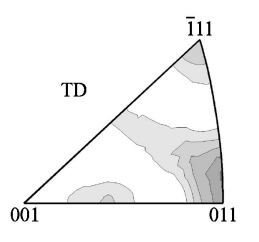

Fig. 5 Inverse pole figures along different directions in the rolling plane for the cold rolled (a) Ti-18Zr-16Nb (at\%) and (b) Ti-18Zr-18Nb (at\%) alloys.

The orientation dependence of Young's modulus in $\beta$-type $\mathrm{Ti}$ alloys has been investigated in the Ti-22Nb-6Ta ${ }^{12)}$ (at \%) and $\mathrm{Ti}-24 \mathrm{Nb}-3 \mathrm{Al}^{13}$ ) (at\%) alloys: the Young's modulus exhibits the maximum value along $\langle 111\rangle$ and the minimum value along $\langle 001\rangle$. The effect of the deformation textures on the in-plane anisotropy of the Young's modulus for the Ti$18 \mathrm{Zr}-(16,18) \mathrm{Nb}$ (at \%) alloys is discussed below using the orientation dependence of Young's modulus and inverse pole figures calculated from the ODFs in Fig. 4. Figure 5 shows the inverse pole figures corresponding to the three directions, the RD, 45D and TD in the Ti-18Zr- $(16,18) \mathrm{Nb}$ (at\%) alloys. There is no strong peak in each inverse pole figure of the Ti-18Zr-16Nb (at\%) alloy, indicating that the texture is weak. As a result, it is considered that the weak anisotropy of the Young's modulus shown in Fig. 2(b) is due to the weak texture formed in the Ti-18Zr-16Nb (at\%) alloy. The slight increase of the Young's modulus from the RD to the TD would be due to that the inverse pole figure corresponding to the TD shows slightly high axis density at $\langle 111\rangle$. On the other hand for the Ti-18Zr-18Nb (at\%) alloy, the inverse pole figures of both the RD and TD show high axis densities at $\langle 011\rangle$, while the inverse pole figure of the $45 \mathrm{D}$ shows high axis density at $\langle 001\rangle$ corresponding to the orientation with the lowest Young's modulus. It can be explained using this result that the Young's moduli along the RD and TD shown in Fig. 2(d) are almost same, while the Young's modulus along the $45 \mathrm{D}$ is low in comparison with the RD and TD.

TEM observation was conducted in order to investigate the internal structures of the $99 \%$ cold rolled specimens. Figure 6 shows the bright field images and the corresponding selected area diffraction patterns of the Ti-18Zr- $(16,18) \mathrm{Nb}$ (at\%) alloys. It is confirmed from these diffraction patterns that both alloys consist of only $\beta$ phase. Referring to the diffraction pattern of the Ti-18Zr-18Nb (at\%) alloy, the diffraction spots indicated by white arrows are double diffraction spots. The Ti-18Zr-16Nb (at\%) alloy reveals extremely fine structure. The diffraction pattern of the alloy shows continuous ring pattern, indicating that the alloy is composed of small grains with various orientations. This result is consistent with the fact that the alloy exhibits the weak deformation texture as shown in Fig. 4(a). On the other 
(a) $\mathrm{Ti}-18 \mathrm{Zr}-16 \mathrm{Nb}$

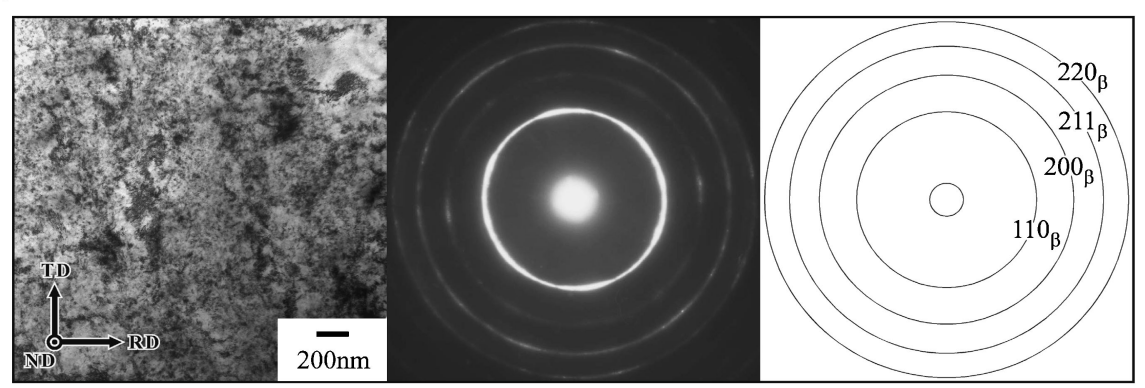

(b) $\mathrm{Ti}-18 \mathrm{Zr}-18 \mathrm{Nb}$

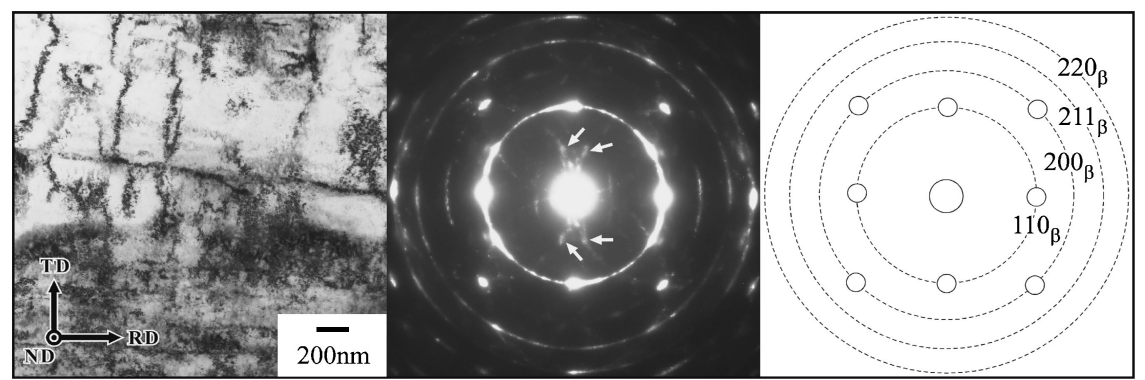

Fig. 6 Bright field TEM images and the corresponding selected area diffraction patterns of the cold rolled (a) Ti-18Zr-16Nb (at\%) and (b) Ti-18Zr-18Nb (at\%) alloys.

hand in the Ti-18Zr-18Nb (at\%) alloy, such a fine structure was not formed but the high density of dislocations is observed. It is considered that the higher tensile strength of the $\mathrm{Ti}-18 \mathrm{Zr}-16 \mathrm{Nb}$ (at\%) alloy is due to the fine structure when compared with the Ti-18Zr-18Nb (at\%) alloy.

As stated above, the deformation texture and internal structure of the $\mathrm{Ti}-18 \mathrm{Zr}-16 \mathrm{Nb}$ (at\%) alloy are different from those of the $\mathrm{Ti}-18 \mathrm{Zr}-18 \mathrm{Nb}$ (at\%) alloy. It is considered that the differences are due to the different deformation mechanisms during cold rolling in both alloys. It has been reported that alloy composition strongly affects a martensitic transformation temperature of the $\mathrm{Ti}-\mathrm{Nb}$ alloy and the addition of $1 \mathrm{at} \% \mathrm{Nb}$ decreases the martensitic transformation start temperature $\left(M_{\mathrm{s}}\right)$ about $40 \mathrm{~K} .{ }^{17)}$ Therefore, $\beta$ phase stability of the $\mathrm{Ti}-18 \mathrm{Zr}-16 \mathrm{Nb}($ at $\%)$ alloy at room temperature is lower compared with that of the Ti-18Zr-18Nb (at\%) alloy, suggesting that the martensite phase is easily stress-induced during rolling in the Ti-18Zr-16 Nb (at\%) alloy. Meanwhile, extremely fine deformed structure similar to that of the Ti$18 \mathrm{Zr}-16 \mathrm{Nb}$ (at\%) alloy was also reported in a $\beta$-type Ti-NbTa-In alloy exhibiting low $\beta$ phase stability. ${ }^{18)}$ As a result, it is suggested that different textures and microstructures between the $\mathrm{Ti}-18 \mathrm{Zr}-16 \mathrm{Nb}$ (at\%) and $\mathrm{Ti}-18 \mathrm{Zr}-18 \mathrm{Nb}$ (at \%) alloys are related to the $\beta$ phase stability and the stressinduced martensitic transformation during rolling. However, details are not clear at this stage, and further investigation is now in progress.

\subsection{Young's modulus and tensile strength}

The Young's modulus and tensile strength of the $99 \%$ cold rolled $\mathrm{Ti}-18 \mathrm{Zr}-16 \mathrm{Nb}$ (at\%) alloy along the RD were compared with those of conventional biomedical Ti alloys, ${ }^{1,2)}$ such as CP-Ti ( $\alpha$-type Ti), Ti-6Al-4V (mass $\%)$ alloy $(\alpha+\beta$ type alloy) and $\mathrm{Ti}-13 \mathrm{Nb}-13 \mathrm{Zr}$ (mass $\%)$ alloy ( $\beta$-type alloy),

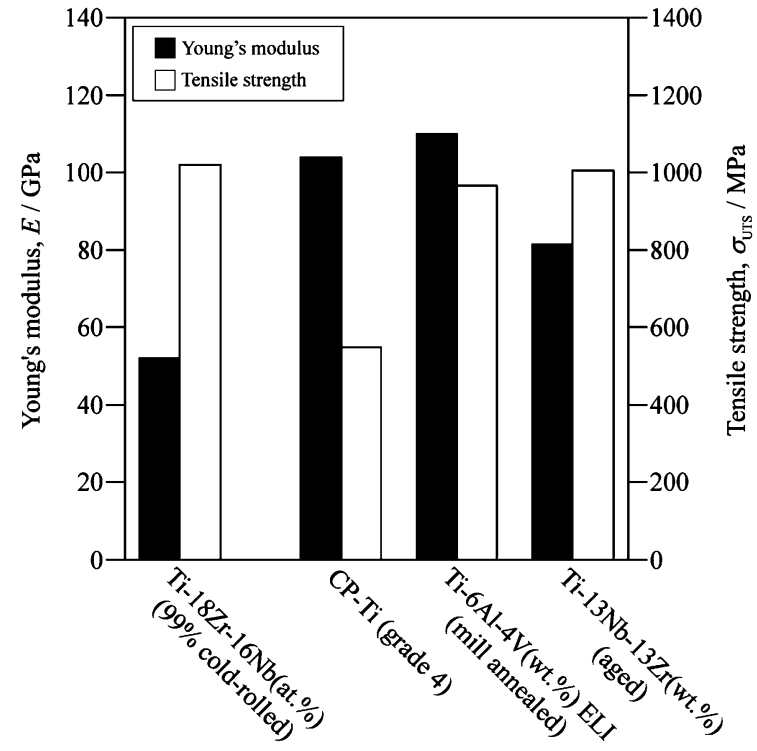

Fig. 7 Young's modulus and tensile strength of the cold rolled Ti-18Zr$16 \mathrm{Nb}(\mathrm{at} \%)$ alloy in comparison with some biomedical Ti alloys.

in Fig. 7. The Young's moduli of the CP-Ti and Ti-6Al-4V (mass\%) alloy are over $100 \mathrm{GPa}$, which is much higher than that of human bone ( $\sim 30 \mathrm{GPa})$. The $\beta$-type Ti-13Nb-13Zr (mass\%) alloy exhibits a lower Young's modulus of $80 \mathrm{GPa}$ compared with the CP-Ti and Ti-6Al-4V (mass\%) alloy, but it is still higher than that of human bone. The Ti-18Zr-16Nb (at\%) alloy exhibits much lower Young's modulus than the Ti-13Nb-13Zr (mass\%) alloy and the value of the Young's modulus of about $50 \mathrm{GPa}$ is closer to that of human bone. The low Young's modulus of the Ti-18Zr-16Nb (at\%) alloy is due to the fact that the $M_{\mathrm{s}}$ of the alloy is close to room temperature. It has been reported that the $\beta$-type Ti alloys 
with $M_{\mathrm{s}}$ close to room temperature exhibit the minimum Young's modulus at room temperature due to the instability of the $\beta$ phase. ${ }^{14,15)}$ Referring to the tensile strength, the Ti$18 \mathrm{Zr}-16 \mathrm{Nb}($ at\%) alloy exhibits a high strength over $1 \mathrm{GPa}$ which is comparable to the conventional alloys. In general, low Young's modulus and high strength are contradicting properties, however the $\mathrm{Ti}-18 \mathrm{Zr}-16 \mathrm{Nb}$ (at\%) alloy reveals both the low Young's modulus and high strength due to the instability of the $\beta$ phase and the fine structure formed by cold rolling, respectively.

\section{Conclusions}

(1) All the Ti-18Zr-(15 18)Nb (at\%) alloys exhibited low Young's modulus of about 50 60 GPa. The anisotropy of the Young's modulus was weak in the Ti-18Zr$(15,16) \mathrm{Nb}($ at\% $)$ alloys, whereas the Young's modulus of the $\mathrm{Ti}-18 \mathrm{Zr}-18 \mathrm{Nb}$ (at\%) alloy exhibited a strong orientation dependence.

(2) A weak $\gamma$-fiber texture was observed in the $\mathrm{Ti}-18 \mathrm{Zr}$ $16 \mathrm{Nb}($ at $\%)$ alloy. On the other hand, a well developed $\{001\}\langle 110\rangle$ texture was observed in the Ti-18Zr-18Nb (at\%) alloy.

(3) The Ti-18Zr-16Nb (at\%) alloy exhibited extremely fine structure, resulting in the high tensile strength over $1 \mathrm{GPa}$. The Ti-18Zr-16Nb (at\%) alloy exhibited both a high strength comparable to the conventional Ti alloys and a lower Young's modulus comparable to the human bone.

\section{Acknowledgement}

This work was partially supported by the Grants-in-Aid for Fundamental Science Research (Wakate B(2006-2007), Kiban C(2008-2010)) from the Ministry of Education, Culture, Sports, Science and Technology, Japan and the Grant-in-Aid for JSPS Fellows from the Japan Society for the Promotion of Science. This work was also partially supported by WCU (World Class University) program through the National Research Foundation of Korea funded by the Ministry of Education, Science and Technology (grant number: R32-2008-000-20093-0).

\section{REFERENCES}

1) M. Niinomi: Mater. Sci. Eng. A 243 (1998) 231-236.

2) K. Wang: Mater. Sci. Eng. A 213 (1996) 134-137.

3) S. Miyazaki and H. Y. Kim: Mater. Sci. Forum 561-565 (2007) 5-21.

4) Y. Fukui, T. Inamura, H. Hosoda, K. Wakashima and S. Miyazaki: Mater. Trans. 45 (2004) 1077-1082.

5) E. Takahashi, T. Sakurai, S. Watanabe, N. Masahashi and S. Hanada: Mater. Trans. 43 (2002) 2978-2983.

6) T. Maeshima and M. Nishida: Mater. Trans. 45 (2004) 1096-1100.

7) H. Y. Kim, Y. Ohmatsu, J. I. Kim, H. Hosoda and S. Miyazaki: Mater. Trans. 45 (2004) 1090-1095.

8) H. Y. Kim, S. Hashimoto, J. I. Kim, T. Inamura, H. Hosoda and S. Miyazaki: Mater. Sci. Eng. A 417 (2006) 120-128.

9) J. I. Kim, H. Y. Kim, T. Inamura, H. Hosoda and S. Miyazaki: Mater. Sci. Eng. A 403 (2005) 334-339.

10) H. Y. Kim, N. Oshika, J. I. Kim, T. Inamura, H. Hosoda and S. Miyazaki: Mater. Trans. 48 (2007) 400-406.

11) J. I. Kim, H. Y. Kim, H. Hosoda and S. Miyazaki: Mater. Trans. 46 (2005) 852-857.

12) H. Y. Kim, T. Sasaki, K. Okutsu, J. I. Kim, T. Inamura, H. Hosoda and S. Miyazaki: Acta Mater. 54 (2006) 423-433.

13) T. Inamura, Y. Kinoshita, J. I. Kim, H. Y. Kim, H. Hosoda, K. Wakashima and S. Miyazaki: Mater. Sci. Eng. A 438-440 (2005) 865869.

14) T. Inamura, H. Hosoda, K. Wakashima and S. Miyazaki: Mater. Trans. 46 (2005) 1597-1603.

15) H. Matsumoto, S. Watanabe and S. Hanada: Mater. Trans. 46 (2005) 1070-1078.

16) H. Tobe, H. Y. Kim, T. Inamura, H. Hosoda and S. Miyazaki: Proc. 11th World Conf. on Titanium, (The Japan Inst. Metals, 2007) pp. 1451-1452.

17) H. Y. Kim, H. Satoru, J. I. Kim, H. Hosoda and S. Miyazaki: Mater. Trans. 45 (2004) 2443-2448.

18) W. Xu, K. B. Kim, J. Das, M. Calin, B. Rellinghaus and J. Eckert: Appl. Phys. Lett. 89 (2006) 031906. 